\title{
Pipeline wear solution at Kidd Mine: energy absorbent ceramic composites
}

\author{
A. White Xstrata Copper, Canada \\ M. McGuinness Paterson \& Cooke, Canada \\ V. Newman Xstrata Copper, Canada
}

\begin{abstract}
Pipeline wear is an important consideration in the design and operation of paste fill distribution systems. The more significant the wear, the more time and money is invested in tracking it, replacing worn or failed pipe, and at times even modifying the distribution system to adapt to it. At Xstrata Copper's Kidd Mine, much higher wear rates were experienced than anticipated during original design of the system. Much has been learned about pipeline wear during eight years of paste fill at Kidd, and that knowledge, together with increased confidence in bonding properties and wear resistance of energy absorbent ceramic composite pipe linings, has led to a recent change in strategy.
\end{abstract}

This paper presents this move away from ongoing wear-adaptive system changes to investing in a life-ofmine (LOM) ceramic composite-lined distribution system at the Kidd Mine. Important aspects of the business case are described, including recent experience with these linings in system boreholes, a cash flow comparison with traditional Schedule 80 piping, and soft benefits of a wear resistant system. Also discussed are some key operational and technical items to be addressed as part of the transition to ceramic polymer composite linings.

\section{Introduction}

Wear is a common problem in pipeline systems, resulting in production loss and high maintenance costs. Low-density slurry systems rely on turbulent flow and high velocities to keep particles in suspension. These conditions often produce high wear areas in the pipeline. Paste fill, being a high-density material characterised by laminar flow and low velocities, is usually associated with lower pipeline wear (Bloss and Revell, 2000; Steward and Spearing, 1992). However, there are paste fill plants experiencing high wear in their distribution system, resulting in significant downtime and production loss. Some suggested causes of the high wear are the addition of aggregate to the paste fill (Tunstall and Grandfield, 2002; Bruneau and McGuinness, 2008), fill material characteristics (Bloss and Revell, 2000; McGuinness and Cooke, 2011; Steward and Spearing, 1993), high velocities, and free fall of paste in the boreholes (Steward and Spearing, 1992; O'Hearn et al., 2001). The effects of high wear are more than just a maintenance issue; wear can also cause unstable flow in the pipeline. In these cases, much time and money is spent on dealing with the production interruptions resulting from premature pipeline failure and on instigating preventative measures to mitigate the effect of wear in the system. Mitigation measures can include implementing pipe replacement schedules, modifying pipeline hydraulic flow through configuration changes, and switching to a more wear resistant pipe material.

Ideally, the susceptibility to distribution system wear would be identified at the design stage of a paste project. This would allow pipeline wear to be factored into capital and operating cost evaluations, material selection for distribution system piping, and pipeline configuration to minimise the production, safety, and financial risks associated with wear. However, it can be difficult to fully characterise wear rates prior to commissioning due to the multiple factors influencing wear in the pipeline and the uniqueness of each tribosystem (Budinski, 2007; Bahadur and Iskandar, 1992). 
As Kidd Mine has experienced firsthand, the elevated and unexpected operating and maintenance costs associated with high system wear can far exceed the initial capital costs of installing a more robust, wear resistant pipeline. As wear in paste fill systems is increasingly better characterised, pipe materials are being designed to target paste fill applications. This paper discusses the process involved with changing the pipeline material in the Kidd Mine paste fill system as part of a LOM solution to high wear.

\section{Background}

Xstrata Copper's Kidd Mine runs a $1.4 \mathrm{Mt} / \mathrm{yr}$ paste fill operation in Timmins, Ontario. The $400 \mathrm{tph}$ paste fill plant feeds a gravity-fed underground distribution system consisting of over $5 \mathrm{~km}$ of $200 \mathrm{~mm}$ piping that delivers paste to stopes at depths of 500-3,000 m from surface. The paste consists of a mixture of equal parts sand and tailings to which water and binder are added to produce a paste of approximately $83 \%$ solids by mass (Lee and Pieterse, 2005). Initial production analysis confirmed a stable, pressurised distribution system in laminar flow. System pressures showed that during a pour, paste backup was achieved in all boreholes.

The decision to change to wear resistant piping was the result of a process that began in 2006 when the first pipeline thickness measurements were taken. At this time it was noted that the wear rate was much higher than anticipated: a rate of $0.07 \mathrm{~cm} / 100,000$ tonnes of paste. At this rate, the system's API X52 Schedule 80 pipe would reach its minimum allowable thickness (to maintain pipe pressure rating) after approximately $0.8 \mathrm{Mt}$ of paste production, requiring annual change out. A comprehensive description of the Kidd Mine paste fill system and this initial experience with high pipeline wear was published in 2011 (McGuinness and Cooke, 2011).

Significant time and energy has been invested to characterise and understand the wear and troubleshoot the problems created by it. The repercussions of worn pipe were farther reaching than just pipe replacement requirements:

- Wear of boreholes beyond the casing and into the host rock resulted in water infiltration, which affected paste quality and increased flow rates.

- Significant wear increased the internal diameter of the boreholes, resulting in lower friction losses in the system. This produced slack flow and led to pipe hammer as parts of the system transitioned between pressurised and vacuum states.

- As boreholes wore into host rock, the casing often peeled and resulted in frequent plugging of the distribution system (see Figure 1).

- Increased preventive and corrective maintenance, involving frequent pipeline inspections (nondestructive testing) and replacement of worn pipe, strained the production capability of the system.

- A detailed account of the effects of wear on the paste fill operation and distribution system hydraulics was presented at the Minefill conference in 2011 (McGuinness and Cooke, 2011). 

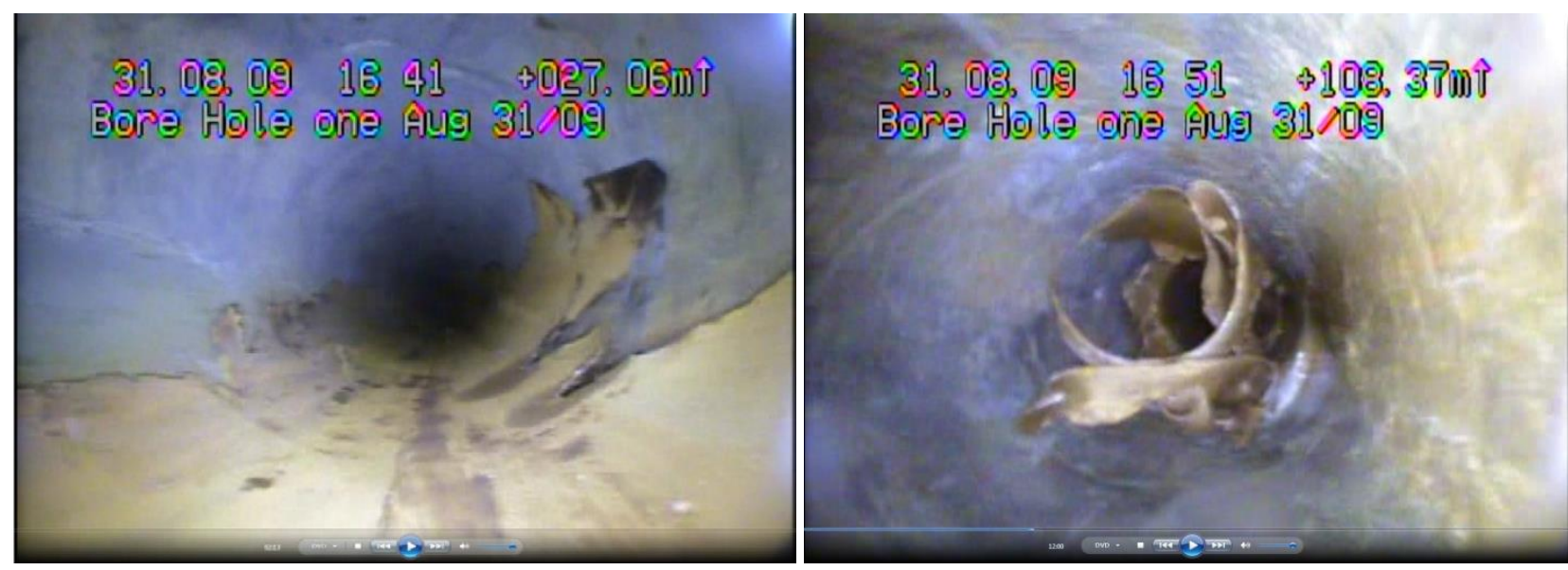

\section{Figure 1 Borehole wear beyond casing into host rock (left) and peeled casing resulting in blockage (right)}

Several types of pipe were tested in the paste distribution system at Kidd Mine, including induction hardened, twin-wall, ceramic, and carbon-overlay. These in situ tests were the most representative evaluation of the pipe performance in this particular wear environment. Benchmarking of other paste fill operations was also instrumental in the evaluation and selection of a new pipe material. While a thorough assessment of costs for each option was critical, the selection process also included technical performance, benchmarking, and operational considerations. Ceramic materials performed well in the aggressive wear environment of the paste fill distribution system and several types of ceramic were evaluated. The high bonding and positive wear results of IMATECH's 7500 Series ArmorPIPE ${ }^{\mathrm{TM}}$ led to its selection as the most economical solution and to the decision to use this pipe in all boreholes being drilled to replace worn casing in the upper mine and in all new boreholes required for mine expansion. This decision was also supported by positive reviews from Xstrata Copper Mount Isa Mines, which uses this ceramic lined pipe under similar conditions in its paste fill and hydraulic fill systems.

\section{Performance of ceramic lined boreholes}

Ceramic lined borehole casing could not be installed in the same manner as the unlined casing, as the unlined casing had welded joints and the ceramic lined casings were threaded. Most of the damage occurring during transport and installation was limited to the threaded ends and did not impact the ceramic composite lining. Any lining that was damaged was generally repaired using patch techniques in the field.

To date, all boreholes have been drilled and cased, and the majority are now in operation. The longest operating borehole, which is also expected to see the highest wear, is from surface to $487 \mathrm{~m}$ underground and has seen a paste throughput of $3.48 \mathrm{Mt}$.

An acoustic televiewer survey conducted by DGI Geoscience indicates that lining wear in this borehole is occurring at average rates slightly below original expectations. The survey, which provided measurements of internal diameter at one $\mathrm{cm}$ intervals, shows an average lining wear rate of $0.92 \mathrm{~mm} / \mathrm{Mt}$ versus a design of $1.1 \mathrm{~mm} / \mathrm{Mt}$. Wear rates were highest near the top of the borehole, as the underground distribution system (UDS) is gravity fed, which requires pressures at surface to be near zero and results in the top of the borehole routinely operating in slack flow. Average wear results throughout this borehole are shown in Table 1, along with portion of the pipe showing elevated wear. 
Table 1 Summary of acoustic televiewer survey results in ceramic lined borehole from surface to $487 \mathrm{~m}$ underground after $3.48 \mathrm{Mt}$ of paste fill service

\begin{tabular}{lccc}
\hline Depth $(\mathbf{m})$ & $\begin{array}{c}\text { Average lining } \\
\text { wear }(\mathbf{m m})\end{array}$ & $\begin{array}{c}\text { Average rate of lining } \\
\text { wear }(\mathbf{m m} / \mathbf{M t})\end{array}$ & $\begin{array}{c}\text { Lining wear in excess of } \\
\mathbf{1 . 3} \mathbf{~ m m} / \mathbf{M t} \text { (\% readings) }\end{array}$ \\
\hline 30 to 80 & 3.5 & 1.01 & $11.6 \%$ \\
80 to 130 & 2.8 & 0.80 & $1.6 \%$ \\
130 to 180 & 3.0 & 0.85 & $0.1 \%$ \\
180 to 230 & 3.0 & 0.85 & $3.6 \%$ \\
230 to 280 & 3.2 & 0.92 & $3.5 \%$ \\
280 to 330 & 3.2 & 0.91 & $2.3 \%$ \\
330 to 380 & 3.2 & 0.92 & $2.6 \%$ \\
380 to 430 & 3.2 & 0.92 & $2.8 \%$ \\
430 to 480 & 3.3 & 0.95 & $4.6 \%$ \\
\hline
\end{tabular}

Monitoring of the boreholes is also conducted using a winch-mounted camera. These inspections have detected some minor localised defects to be further investigated, as well as a small amount of water ingress at many of the threaded joints (see Figure 2). It is believed that the defects may result from air entrapment in the surface of the lining, but this is currently unconfirmed. They do not appear to have any significant effect on the wear properties or the lining adhesion of the larger system. Camera surveys conducted prior to use and within the first year of service indicate that the above-mentioned defects were noticed and do not appear to have gotten worse. The water ingress at the joints was also noticed in the boreholes post commissioning and does appear to have increased with service. This quantity of water is negligible when compared to that observed during wear of previous boreholes beyond the steel casing and into the host rock, and has not resulted in any noticeable effect on paste flow.
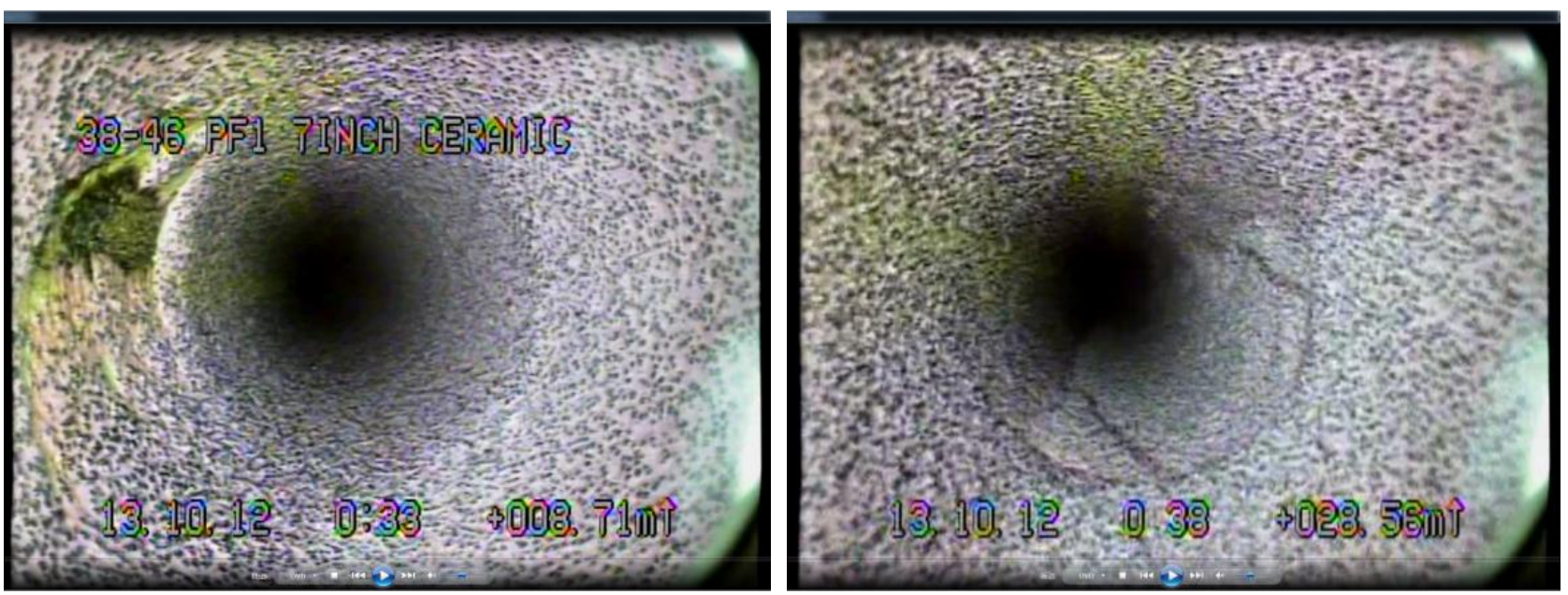

\section{Figure 2 Minor localised damage of ceramic lining in borehole (left) and small ingress of water at threaded joints in borehole (right)}

Increased local wear has been detected at some of the transitions from lateral piping to vertical boreholes. This is easily inspected and repaired by removing the elbow and patching with a higher grade composite where required (see Figure 3). If necessary, the flanged section of the casing could be replaced with one lined with a higher grade of composite; however, this has yet to be required as the patch material is performing well. The impact on these sections can also be reduced by creating a more gradual transition to and from the vertical boreholes. 

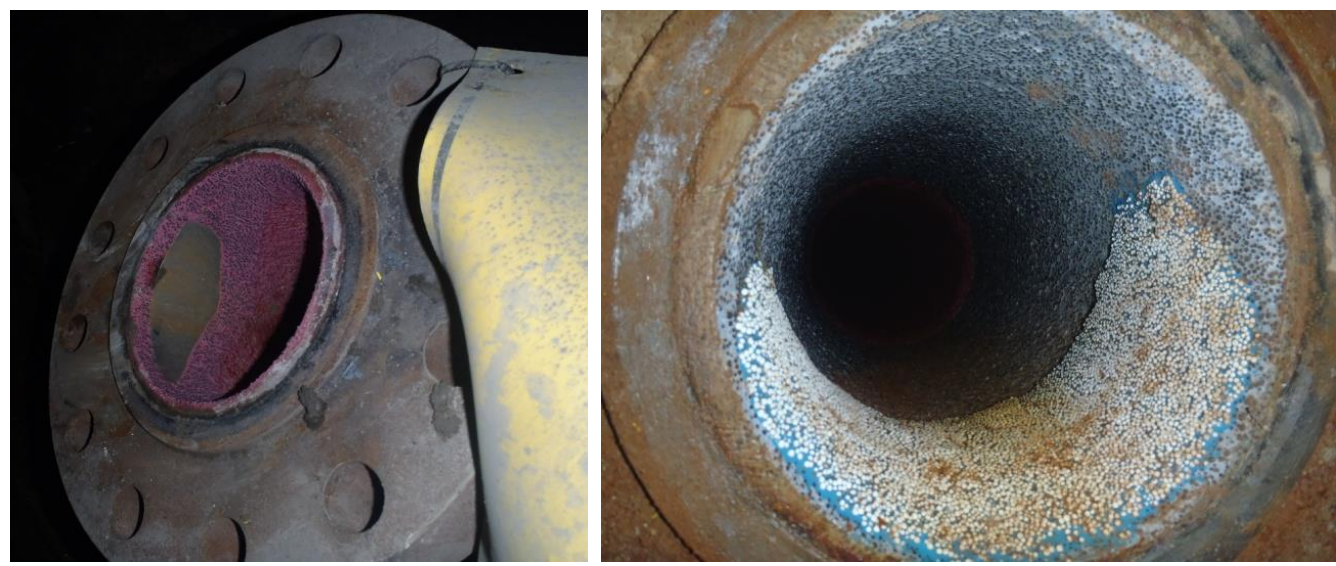

Figure 3 Increased ceramic wear localised at transition from loop to borehole (left) and
patch of similar wear after $1.5 \mathrm{Mt}$ of paste fill service (right)

\section{$4 \quad$ Transition to ceramic lined loop piping}

With increasing confidence in the IMATECH pipe lined with energy absorbent ceramic composite, the business case was made for the replacement of Schedule 80 pipe with IMATECH pipe in the primary horizontal loops at Kidd Mine.

\subsection{Advantages and disadvantages}

At Kidd Mine, the primary benefit of further transitioning to ceramic composite linings and away from traditional steel piping is the reduction in ongoing construction scope. Projections show that annual replacement of worn Schedule 80 loop piping would average in excess of 1,000 m (roughly 2/3 of primary distribution system) until mine closure (currently scheduled for 2020). Extended pipe life resulting from increased wear resistance will mean a primary system designed to last the remaining seven to eight years of mine life and will require little to no replacement of worn pipe. Even with the added expense of this high wear piping (4:1 versus Schedule 80$)$, the reduction in contract labour and Schedule 80 replacement piping costs is conservatively estimated to yield an internal rate of return of $25-30 \%$, with a payback period of less than three years.

Another benefit is the ability to vary matrix composition and lining thickness of these ceramic composites to better provide economic, application-specific solutions. Although lower grades of IMATECH pipe were considered, the 7500 Series ArmorPIPE ${ }^{\mathrm{TM}}$ was once again selected, as it provides both acceptable return on investment and 'set it and forget it' maintenance. In selecting the desired lining thickness, expected paste fill service through LOM was assessed for each individual loop section. Care was taken to include some additional capacity, which should prevent pipe replacement requirements from deterring a later decision to extend mine life. In the end, two specifications of pipe were selected: while both are Schedule 40, the lining thicknesses will be $5 \mathrm{~mm}$ and $10 \mathrm{~mm}$ respectively. Given the composite grade selected and the paste fill characteristics at Kidd Mine, the corresponding service ratings are $5 \mathrm{Mt}$ and $10 \mathrm{Mt}$. Refer to Table 2 for a summary of the piping design for primary loop at Kidd Mine.

Table 2 IMATECH 7500 series design for Kidd Mine primary loop

\begin{tabular}{cccc}
\hline $\begin{array}{c}\text { Designed service } \\
\mathbf{( 1 , 0 0 0} \text { tonnes of paste) }\end{array}$ & $\begin{array}{c}\text { Lining thickness } \\
\text { (millimetres) }\end{array}$ & $\begin{array}{c}\text { Expected service - average } \\
(\mathbf{1 , 0 0 0} \text { tonnes of paste) }\end{array}$ & $\begin{array}{c}\text { Total pipeline } \\
\text { length (metres) }\end{array}$ \\
\hline 10,000 & 10 & 8,980 & 760 \\
5,000 & 5 & 1,640 & 660 \\
\hline
\end{tabular}

As a result of the increased wear resistance, a well-designed system should remain static for a much longer period than a steel system. At Kidd, this allowed production profiles and stope sequencing data to be used 
in a more confident tailoring of loop design to balance flow and system pressures through to LOM. This involved flow modelling at a series of pour depths and final level piping lengths to determine the optimum balance. This well-defined static system will also enable more accurate characterisation of paste rheology and understanding of system behaviour.

As is prudent with an internal pipe lining, the potential for lining to peel from the host pipe and result in blockage was considered:

"The bond strength of the lining to the substrate should exceed the force of oxidation (the pressure at which rust forms and continues to oxidise). This figure is nominally $2100 \mathrm{psi}$. The reality is that all linings due to any number of reasons could at some stage be mechanically damaged, abraded, or subject to process conditions outside of the normal operating curve, resulting in exposure of the host pipe. Linings that have a poor bond suffer from 'underfilm corrosion' (the migration of rust beneath the lining), and will likely cause it to crack/disbond. Particularly in an environment such as an underground paste fill distribution system, increasing the risk of a blockage due to lining delamination is not an option." Marcus Smith, IMATECH (personal communication with the author, 28 January 2013)

Experience with these energy absorbent ceramic composite linings in borehole piping at Kidd Mine has shown no evidence of lining separation through 3.48 million tonnes of paste fill service. Testing of teeblasting procedures on this lined piping (discussed further in Section 4.2) also evidenced a strong bond of the composite to the steel.

Traditional methods for measuring pipe wear, such as external non-destructive testing with an ultrasonic thickness gauge, will no longer be effective, as it is now the thickness of the internal lining that is of concern. Internal non-destructive testing methods using a camera, calliper, acoustic televiewer, or IMATECH's IPIPE $^{\mathrm{TM}}$ laser robot technology, should provide the necessary information, though some of the techniques are more novel and complex. Ultimately, the added time and expense required for internal measurements is offset by the considerable reduction in both the frequency of required inspections and the likelihood that wear exceeds that frequency resulting in failure.

As the relative value of each individual pipe will increase, damage as a result of transport or handling could be costly. Experience at Kidd Mine during borehole installation showed that these lined pipes are in fact quite robust in the underground mining environment. Very few pipes were damaged, with most easily repaired at the installation site.

\subsection{Practical considerations}

To best take advantage of the lining's wear resistance, care will be taken to ensure that changes in pipe direction are as gradual and smooth as is practical. Long radius elbows will be used and particular attention will be given to the transitions to and from vertical boreholes. Construction crews will be trained by IMATECH in proper installation techniques at the outset of the project and quality control inspections will be conducted at defined intervals.

With significantly reduced wear rates, focus is expected to shift towards localised damage. As previously discussed, increased wear localised at lateral to vertical transitions is easily patched using manual techniques. Lining damage may be detected some distance into a section of horizontal or vertical piping, perhaps due to installation factors or feed material contamination (which is not uncommon with historic gold mine tailings used at Kidd Mine). If the damaged pipe is readily accessible, as is the case for the horizontal loop, it can quickly and easily be replaced or repaired. Where access for replacement is not available, e.g. in boreholes, IMATECH is exploring technologies for in situ patching.

Straight pipe will be supplied in three metre lengths, grooved at each end to accommodate the desired Victaulic coupling. Local cutting and grooving of shorter custom lengths from these larger pipes will be necessary. This will require some modification of the cutting and grooving techniques employed for the 
current Schedule 80 pipe. New diamond saw blades will be procured for cutting and a lathe will be procured for grooving, as the current pipe grooving machine requires a smooth internal surface.

The Kidd Mine procedure for unplugging a blockage of paste in the distribution system involves the use of blasting tees installed throughout the system. These are essentially short lengths of pipe fitted with a $75 \mathrm{~mm}$ nipple, from which a cap can be removed through blasting to allow drainage of paste above a blockage. Field testing was conducted to understand the potential lining damage in the surrounding pipes when blasting at the tee and also directly at the clamps. Results showed that even when blasting the clamps, the extent of the damage to the ceramic lining in the surrounding pipes was minimal and evidenced a strong bond to the pipe (see Figure 4). The most significant damage occurred during tests conducted on an empty system, and this was still relatively minor. Damage is expected to be less significant when the system is charged with paste. The decision was taken to make blasting at the clamps the new standard as it provides a greater chance of clearing the blockage and does not require lining of specialty tee pieces. Any damage to the lining of the adjacent pipes will be patched if possible; otherwise, the pipe will be cut down for use in shorter custom lengths. It is important to note that, while system blockages were at one time quite frequent at Kidd, improved controls, particularly around feed material contamination, have almost eliminated these events.

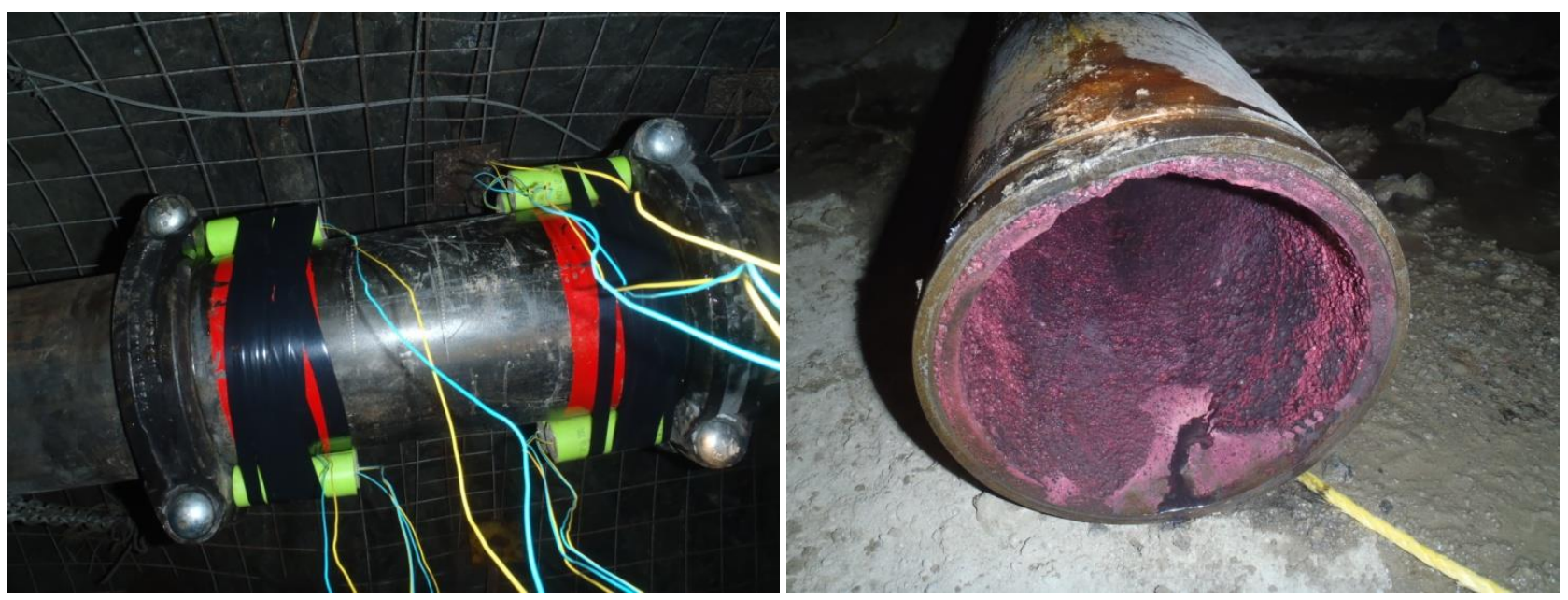

\section{Figure 4 Setup for test blast of clean-out tee clamps (left) and extent of damage to adjacent pipe lined with energy absorbent ceramic composite (right)}

\section{Application}

The application of energy absorbent ceramic composite linings in paste fill distribution may provide significant benefit, particularly for high wear or high throughput operations. Although this lined piping can be anywhere from three to five times higher in cost than traditional steel pipe, it is important to consider the cost of the physical replacement or installation. Experience at Kidd Mine has shown these installation costs to be approximately $75 \%$ of total piping costs.

Boreholes warrant particular consideration, as the installation costs can easily double when compared to the cost of the same pipe in a lateral application. Extending borehole life is also important, given the potential for repeated flow obstruction as wear is experienced through the pipe and into the host rock. Wear into the host rock can result in increased wear rates and a host of other issues as quality plug flow is lost.

Medium wear or medium throughput applications should not be discounted, as costs do scale with the composition and thickness required. As confidence in the technology grows, new and novel applications are likely. 


\section{Conclusion}

High wear rates experienced in the paste fill distribution system at Xstrata Copper - Kidd Mine have resulted in considerable investment to date in monitoring, troubleshooting, and correcting the effects of pipe wear on the distribution infrastructure, system operating pressures, and paste flow.

Positive laboratory and field testing results led to the installation of energy absorbent ceramic composites (IMATECH 7500 series) in all primary vertical boreholes. After $3.48 \mathrm{Mt}$ of paste fill throughput in the first commissioned boreholes, wear rates and lining bond properties have been shown to meet or exceed design criteria. Confidence in the material has since resulted in the decision to install this lined piping in all primary horizontal loop sections.

The resulting cost savings in installation labour and replacement materials is significant, with added benefits of increased operational stability and reduced preventive maintenance pressure. This change will, however, require some modification of installation, operation, and maintenance practices.

The potential long-term financial benefit of these pipe linings should not be overlooked due to capital or operating cost pressures of the day.

\section{Acknowledgements}

The authors would like to acknowledge Marcus Smith (IMATECH), Anthony Davis (IMATECH), Dan Vallee (Xstrata), Guy Pelchat (Xstrata), DGI Geoscience, and the Kidd Mine construction crews for their support of the ongoing project and their assistance in data collection.

\section{References}

Bloss, M. and Revell, M. (2000) Cannington paste fill system - Achieving demand capacity, in Proceedings MassMin2000, G. Chitombo (ed), 29 October to 2 November 2000, Brisbane, Australia, Australasian Institute of Mining and Metallurgy, Melbourne, pp. 713-720.

Bruneau, C. and McGuinness, M. (2008) Paste fill operation at Xstrata Copper - Kidd Mine, in Proceedings Maintenance Engineering/Mine Operator's Conference (MEMO 2008), 24-28 February, 2008, CIM, Val d'Or, Quebec, Canada, pp. 50-56.

Budinski, K.G. (2007) Identification of different types of wear, Chapter 1 in Guide to friction, wear and erosion testing, ASTM International, West Conshohocken, PA, pp. 1-15.

Bahadur, S. and Iskandar, I. (1992) Effect of test variables on the friction and wear of alumina, in Proceedings Symposium on Wear Testing of Advanced Materials, 14 November 1992, R. Divakar and P.J. Blau (eds), San Antonio, USA, ASTM committee G-2 on Wear and Erosion, pp. 7-23.

Lee, C. and Pieterse, E. (2005) Commissioning and operating experience with a $400 \mathrm{t} / \mathrm{h}$ paste backfill system at Kidd Creek Mine, in Proceedings Eighth International Seminar on Paste and Thickened Tailings (Paste05), R.J. Jewell and S. Barrera (eds), 20-22 April 2005, Santiago, Chile, Australian Centre for Geomechanics, Perth, pp. 299-316.

McGuinness, M. and Cooke, R. (2011) Pipeline wear and the hydraulic performance of paste fill distribution systems: The Kidd Mine experience, in Proceedings 10th International Symposium on Mining with Backfill "Fill or Fail" (Minefill 2011), 21-25 March 2011, H.J. Ilgner (ed), Cape Town, South Africa, pp. 205-212.

O'Hearn, B., Mackenzie, A. and Rantala, P.A. (2001) Distribution - The weak link in paste backfill, in Proceedings 7th International Symposium on Mining with Backfill (Minefill 2001), D. Stone (ed), Society for Mining, Metallurgy, and Exploration, Inc., Seattle, USA, pp. 263-272.

Steward, N.R. and Spearing, A.J.S. (1992) Wear of backfill pipelines in South African gold mines, in Proceedings 4th International Conference on Bulk Materials Storage, Handling and Transportation and 7th International Symposium on Freight Pipelines, 6-8 July 1992, Wollongong, Australia, IE Australia, pp. 115-121.

Steward, N.R. and Spearing, A.J.S. (1993) The effect of particle sharpness on the wear of backfill pipelines, Journal of the South African Institute of Mining and Metallurgy, South African Institute of Mining and Metallurgy, Vol. 93(5), pp. 129-134.

Tunstall, A.M. and Grandfield, T.J. (2002) Five years with paste fill - Experience at Henty Gold Mine, in Proceedings 8th AusIMM Underground Operators' Conference: Growing our Underground Operations, 29-31 July 2002, Townsville, Australia, Australasian Institute of Mining and Metallurgy, pp. 167-170. 